\title{
A framework for evaluating the consumption patterns and environmental impacts of irrigation methods: a case study from South-Eastern Australia
}

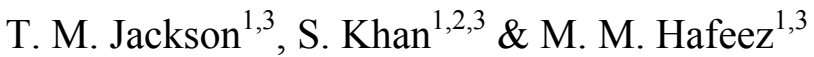 \\ ${ }^{1}$ International Centre of Water for Food Security, \\ Charles Sturt University, Australia \\ ${ }^{2}$ CSIRO Land and Water, Australia \\ ${ }^{3}$ Co-operative Research Centre for Irrigation Futures, Australia
}

\begin{abstract}
Irrigated agriculture is an essential tool for increasing food production to meet global demand. However, along with benefits of high yields there are environmental impacts that must be considered. The tendency in Australia to evaluate irrigation systems in terms of water use efficiency only is problematic, and the criteria used to assess the sustainability of agricultural systems should reflect broader issues. A representative broad acre farm in the south east of Australia was used as a case study to explore the different resource consumption patterns and environmental impacts of flood, centre pivot and sub-surface drip irrigation methods. The energy and water consumption of each method was determined, along with greenhouse gas emissions and groundwater impacts, and the systems then ranked in order of highest to lowest resource use efficiency and environmental impact. It was found that when an irrigated system was evaluated by more than just water use efficiency, its ranking often changed. This method also allowed for the identification of areas where improvements could be made. Assessing irrigation methods and their appropriate selection for a given situation can aid in efficient and environmentally sound production systems at the local and global scale.
\end{abstract}

Keywords: energy, water, environmental impacts, indicators. 


\section{Introduction}

At both national and global levels, concerns over the state of the environment are well established throughout the wider community, including issues such as salinity, water shortages, energy use and carbon emissions. From an agricultural perspective, these are serious matters that impact greatly on the production of food and fibre. Farming has entered a new era, whereby it is not simply enough that a farm produce food and fibre as economic goods; there is now a second important function for farms, which is to produce or protect environmental services [1]. With an increasing public awareness of the environmental impact resulting from food production, it is becoming more important to consider the associated resource inputs and environmental impacts. In addition to this, population pressure means that food production must increase from current levels. Given that irrigated agriculture can be doubly as productive as rainfed agricultural land [2], it can contribute greatly to increases in food production and is therefore a vital part of world agriculture. However, poorly managed irrigation systems can have detrimental environmental impacts, and it is therefore necessary to conduct irrigated agricultural production in such a way that these environmental impacts are minimised.

It is a common practice in Australia to evaluate the effectiveness of an irrigation system in terms of its water use efficiency, using this figure (often given in $\mathrm{ML} / \mathrm{ha}$ ) as a means for comparing different crops and irrigation methods. However, it is imperative that the criteria used to assess the sustainability of agricultural systems reflect the issues of the time [3]. Major global concerns at present are the need to increase food supply, competition among water users and the threat of global warming due to greenhouse gas emissions. Efficiency therefore needs to be considered in a broader sense, incorporating technical and environmental aspects. Khan et al [4] identify the importance of the paddock as the basic decision-making unit, where choices impact on land and water management and salinity dynamics. A consumptive and environmental assessment is important in order that improvements to systems can be made on a local scale, leading to efficient and environmentally sound production systems at the global scale [5].

This paper uses a basic conceptual structure of an irrigated Lucerne seed production system built in Vensim ${ }^{\mathrm{TM}}$ to understand the consumption patterns and environmental impact of irrigation with regard to water and energy consumption. This allows us to explore how changing climatic patterns affect energy and water consumption and the consequences associated with these changes. Salinity impacts in soil and on the watertable are explored using Swagman Farm ${ }^{\mathrm{TM}}$.

\section{Materials and methods}

In order for farms to achieve the dual goals of production and protection of environmental services, it is essential to develop sound evaluation methods that can be used as decision support tools for sustainable agricultural production. As 
cited by van der Werf et al [1], there are generally five common stages in any given method used to assess the environmental impacts of farms.

1. Defining the broad objective of the method. For the purpose of this study, the broad objective is the evaluation of the environmental impacts resulting from the consumption of energy and water for irrigated crop production at the field scale.

2. Define the environmental objectives. Several environmental impacts linked to energy and water consumption are considered in this paper. These include water and energy consumption, carbon emissions linked to energy use, impacts on soil salinity content and local watertable responses associated with irrigation.

3. Define the system to be analysed. The system to be analysed is three irrigated fields, each using a different irrigation method but located on one farm. Some indirect impacts are considered in terms of indirect energy inputs.

4. Identification of indicators. Inputs and outputs will be considered per unit of area and per unit of input (productivity). Salinity responses will be in change of salinity levels in soil and changes to watertable depth.

5. Calculation of results. Values for each indicator are calculated for the system or in this case the irrigation method used, in order that comparisons can be made.

These methods have been adapted to the field level by defining the objectives as impacts that can be measured at the field scale. These impacts directly affect the farm at both an environmental and production level, and the results of these may influence the decisions made by farmers, making them extremely important at the field/farm scale.

\subsection{Site description}

The study sites are located on an irrigated farm producing Lucerne seed, approximately twenty kilometers south of Keith in South Australia. Three paddocks using different irrigation methods were selected for analysis, with the aim of comparing the differences between flood (F), centre pivot (CP) and sub-surface drip (SSD) irrigation systems. The entire region is dependent on groundwater for irrigation, with bores pumping from the shallow watertable. Groundwater quality is variable, ranging from $1.8 \mathrm{dS} / \mathrm{m}(\mathrm{CP})$ to $4.0 \mathrm{dS} / \mathrm{m}$ (F and SSD).

The region is typified by hot, dry summers and cool, wet winters, with average summer maximum temperatures of 27.5 to $29.9^{\circ} \mathrm{C}$ and mean annual rainfall of $466 \mathrm{~mm}$. There has been a general trend of increasing temperatures and decreasing amounts of rainfall since the 1950s [6], increasing the level of dependence on irrigation for crop production. Soils in the region are generally a combination of sand and calcium carbonate, with small areas of loam and clay. The soil type associated with the study sites was sandy loam over limestone.

\subsection{Data collection}

On-farm data was collected via a survey and personal communication with the farmer. In order to calculate the energy used on-farm, a range of data was 
collected pertaining to irrigation methods, water use and energy consumed for pumping and pressurizing systems, land preparation, machinery operations and fertiliser and chemical application. These inputs were selected based on common categories for the consideration of energy inputs as used in previous studies [7, 8]. Energy categories include diesel, electricity, machinery hours, chemicals, fertiliser and seed. Energy and $\mathrm{CO}_{2}$ equivalents were used to quantify energy inputs and emissions. The values used in this study are shown in Table 1.

Table 1: $\quad$ Energy and $\mathrm{CO}_{2}$ emission co-efficients.

\begin{tabular}{|llcc|l|}
\multicolumn{1}{|c}{ Input } & Unit & $\begin{array}{c}\text { Sequestered } \\
\text { energy (MJ) }\end{array}$ & $\begin{array}{c}\text { Emissions } \\
\left(\mathbf{g C O}^{2} \text { /MJ }\right)\end{array}$ & Reference \\
\hline Diesel & litre & 56.31 & 80.8 & {$[5,8,9]$} \\
Electricity & $\mathrm{kWh}$ & 11.93 & 43.1 & {$[5,9]$} \\
Fertiliser & & & & \\
$\quad$ Nitrogen & $\mathrm{kg}$ & 65 & 50 & {$[10,11]$} \\
$\quad$ Phosphate & $\mathrm{kg}$ & 11.96 & 60 & {$[5]$} \\
$\quad$ Potash & $\mathrm{kg}$ & 11.1 & 60 & {$[12]$} \\
$\quad K_{2}$ O & $\mathrm{kg}$ & 6.7 & 60 & {$[5,12]$} \\
$\quad$ Phosphorous & $\mathrm{kg}$ & 12.44 & 60 & {$[8]$} \\
$\quad$ Potassium & $\mathrm{kg}$ & 11.15 & 60 & {$[8]$} \\
$\quad$ Sulphur & $\mathrm{kg}$ & 5 & 60 & {$[11]$} \\
$\quad$ Lime & $\mathrm{kg}$ & 0.6 & 720 & {$[11]$} \\
Lubricant (Oil) & litre & 47.6 & 43.4 & {$[13]$} \\
Fungicide & $\mathrm{kg}$ & 92 & 60 & {$[10]$} \\
Herbicide & $\mathrm{kg}$ & 240 & 60 & {$[10]$} \\
Insecticide & $\mathrm{kg}$ & 200 & 60 & {$[10]$} \\
Seed - general & $\mathrm{kg}$ & 14 & & {$[10]$} \\
\hline
\end{tabular}

\subsection{Analysis of water and energy productivity}

The Vensim ${ }^{\mathrm{TM}}$ modelling environment was used to construct a model of on-farm energy consumption and greenhouse gas emissions for Lucerne seed production using on-farm data from the study site. Vensim ${ }^{\mathrm{TM}}$ is a visual modelling tool for conceptualising, documenting, simulating, analysing and optimising models of dynamic systems such as farms and irrigated regions. Once a model is built that can be simulated, Vensim ${ }^{\mathrm{TM}}$ allows the behaviour of the model to be thoroughly explored.

\subsubsection{Water application, pumping energy and emissions}

In order to determine the amount of water applied for each irrigation method, the following procedure was used. The crop water requirement (CWR) for Lucerne seed production for the past six years was determined from regional $\mathrm{ET}_{0}$ and crop factor information [14]. This then resulted in the calculation of net CWR 
from 2001-2007. Finally, to calculate the amount of water applied using each irrigation method, the net CWR was divided by the given efficiency of the irrigation method, resulting in a total amount of water applied by each method $(\mathrm{ML} / \mathrm{ha})$. Energy requirements for pumping were determined using standard equations [15].

\subsubsection{Other inputs and emissions}

Other energy input categories included diesel, fertiliser, chemicals and seed. The energy associated with diesel use was calculated by determining the total number of hours of machinery operations per hectare relating to sowing and fertiliser and chemical application and relating this to the size of the tractor (hp) to calculate litres of diesel. This quantity was then converted to an energy and $\mathrm{CO}_{2}$ emission equivalent using the appropriate conversion factor given in Table 1.

Energy associated with fertiliser inputs was calculated by using the amount of phosphorous and trace element fertiliser applied per unit area and converting this to an energy and $\mathrm{CO}_{2}$ emission equivalent using the appropriate conversion factor given in Table 1.

Energy associated with chemical inputs was calculated by using the amount of herbicide and pesticide applied per unit area and converting this to an energy and $\mathrm{CO}_{2}$ emission equivalent using the appropriate conversion factor given in Table 1.

Seed input energy was averaged over six years, which is the length of certification of a Lucerne seed crop.

\subsection{Calculation of impacts on watertable and soil salinity}

SWAGMAN (Salt, Water and Groundwater Management) Farm $^{\mathrm{TM}}$ is a lumped water balance model that predicts changes in the depth to watertable, salinity of the rootzone and gross margins. As a farm scale hydrologic economic model, it combines agronomic, climatic, irrigation, hydrogeological and economic aspects of irrigated agriculture [16] at a paddock or farm level. For the purposes of this study, the focus was on changes in depth to watertable and rootzone salinity under separate paddocks with different irrigation systems. While there are several other models available for modelling salt and water movement, SWAGMAN Farm ${ }^{\mathrm{TM}}$ is customised for situations of shallow watertables and soil salinity and as such is an appropriate model for this situation. Good agreement between SWAGMAN Farm ${ }^{\mathrm{TM}}$ predictions and field observations has been demonstrated [16], further validating its use in this study.

\subsection{Energy and water productivity}

Productivity refers to the benefits derived from inputs into a system, and physical productivity is a ratio of the quantity of yield produced and the quantity of the input. In this paper, the yield is expressed in terms of mass ( $\mathrm{kg} \mathrm{seed)}$ and the input is represented by the quantity of energy (MJ) or water (ML) used for crop production. Energy productivity is expressed as $\mathrm{kg}$ seed/MJ, while water productivity is expressed as $\mathrm{kg}$ seed/ML. 


\section{Results}

The energy and water consumption patterns change depending on the irrigation method used and the soil water deficit for any given year. Results are shown for the period of the last six years, with the net crop water requirement changing each year according to climatic conditions which drive the soil moisture deficit. The amount of water applied is reliant on net crop water requirement and the efficiency of the system. As the order of assumed efficiency is SSD (0.95), CP $(0.75), \mathrm{F}(0.5)$, this is reflected in the quantity of water applied for each method, as illustrated by Figure 1 .

As shown by Figure 2, energy consumption follows a similar pattern to water application; however, the ranking between the systems is reversed in terms of the quantity of energy consumed. Water productivity is an index of the yield and the amount of water applied (Figure 3). In this situation, the SSD system is more water productive than both $\mathrm{CP}$ and F. Energy productivity is an index of the yield and the amount of energy consumed (Figure 4). F is the most energy productive, since it uses the least amount of energy, followed by SSD and CP. Figure 5 shows emissions, which closely follow water use, as energy for groundwater pumping is the biggest energy input on-farm. The F system has higher emissions followed by the SSD and CP systems.
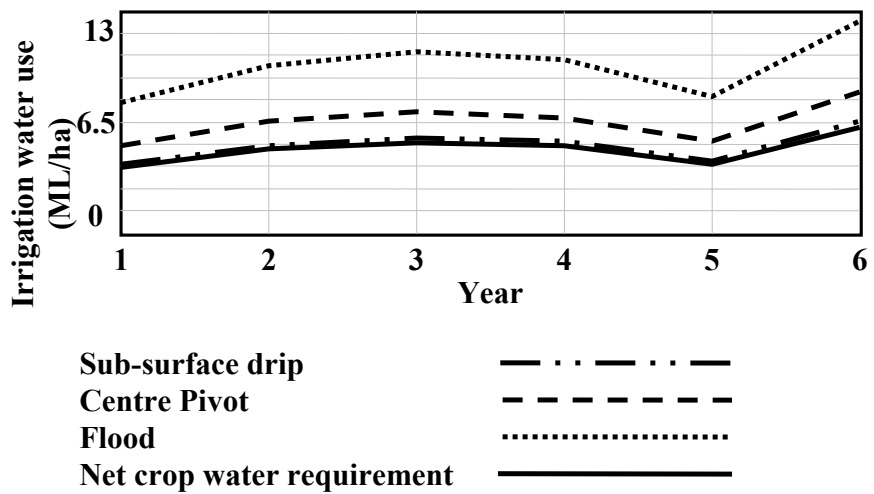

Figure 1: $\quad$ Irrigation water use based on soil water deficit (ML/ha).

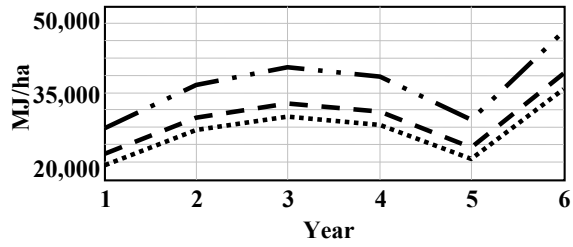

Figure 2: Energy consumption (MJ/ha).

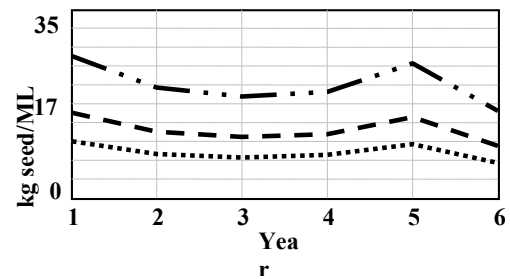

Figure 3: Water productivity. (kg seed/ML). 

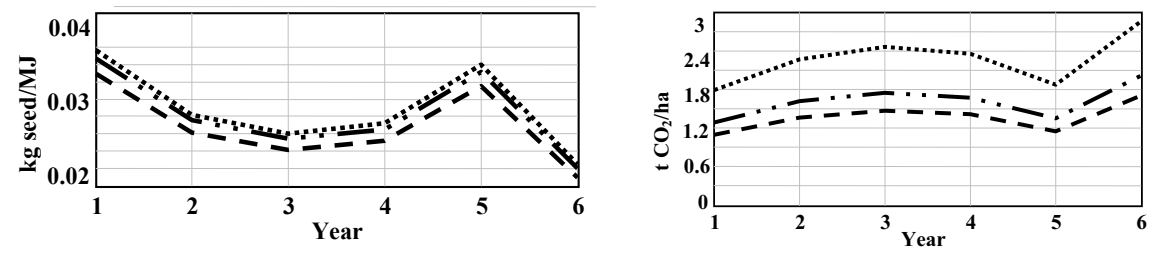

\section{Legend}

Sub-surface Drip_...... Centre Pivot_-_... - Flood.

Figure 4: Energy productivity ( $\mathrm{kg}$ seed/MJ).
Figure 5: $\quad \mathrm{CO}_{2}$ emissions

( $\left.\mathrm{COO}_{2} / \mathrm{ha}\right)$.

Table 2: $\quad$ Changes to groundwater under each irrigation method.

\begin{tabular}{lccr}
\hline Method & $\begin{array}{l}\text { Ave water table } \\
\text { change }(\mathrm{m})\end{array}$ & $\begin{array}{l}\text { Ave soil salt } \\
\text { concentration } \\
(\mathrm{dS} / \mathrm{m})\end{array}$ \\
\hline Flood & -5.65 & 0.16 \\
Centre Pivot & -1.75 & 0.72 \\
Sub surface drip & -0.25 & 1.05 \\
\hline
\end{tabular}

Table 2 shows changes to groundwater under each irrigation method. The extent of the change in soil salinity increases with decreasing water application, while the change in depth to groundwater is greater when more water is removed by pumping.

\section{Discussion}

The results from the Vensim and Swagman models show that the choice of irrigation method and pump fuel source can impact on on-farm productivity and the environment. The amount of water applied is reliant on the soil water deficit and the efficiency of the system. As the order of system efficiency in terms of water delivery is SSD, CP, F, this is reflected in the quantity of water applied for each method, as illustrated by Figure 1. In terms of water use, SSD is the most efficient, followed by $\mathrm{CP}$ and $\mathrm{F}$.

However, when the same systems are assessed from an energy perspective, the opposite is true. As shown by Figure 2, energy consumption follows a similar trend to water application, since groundwater pumping is the largest component of energy consumption. Other inputs are low and remain relatively constant due to the fact that this is a perennial legume that requires no nitrogen fertiliser and land preparation only once every six years. When energy consumption is considered, the ranking between the systems is reversed, due to the fact that SSD and $\mathrm{CP}$ are operated under pressure, which requires a large amount of energy. 
Due to low pressure bubblers being used with the CP, in this situation the SSD system is operated at a higher pressure and hence uses more energy.

Water productivity is an index of the yield and the amount of water applied (Figure 3). In this situation, the SSD system has higher yields $(+25 \%)$ and uses significantly less water than the other systems; consequently, it is more water productive than both $\mathrm{CP}$ and $\mathrm{F}$. The $\mathrm{F}$ system is the least water productive due to its significantly higher water use for no yield gain.

Energy productivity is an index of the yield and the amount of energy consumed (Figure 4). As with energy consumption, energy productivity follows a similar trend to water productivity, as it has been established that energy consumption in this situation is heavily influenced by groundwater pumping. $\mathrm{F}$ is the most energy productive, since it uses the least amount of energy. SSD is the next most energy productive despite its higher energy use due to increased yields, while CP is the least energy productive; despite using less energy than $\mathrm{SSD}$, it has similar yields to the F system.

Greenhouse gas emissions are associated with any energy that is consumed by a system, both direct and indirect. In this situation, emissions closely follow water use, as energy for groundwater pumping is the biggest energy input onfarm (Figure 5). The difference between the systems in this case is that the $\mathrm{F}$ system has higher emissions despite lower energy consumption rates due to the fact that it is supplied by a diesel pump, which has higher associated emissions than electric pumps, which serve the SSD and CP systems.

Groundwater pumping and the subsequent re-application of this water for irrigation impact on the concentration of salt in the rootzone and on the depth to watertable. Based on one average climatic year simulation, the modelled results show that soil salinity increases with decreasing water application. This is due to a reduction in the proportion of water applied that is available for flushing salts from the rootzone. The removal of groundwater also impacts on the depth to watertable. The modelled results show the depth to watertable increasing with higher amounts of water removed, with the largest increase in depth associated with the F system. In reality, the watertable in this region does not change as dramatically as illustrated here. This model does not incorporate lateral or upward flow into the region.

In order to obtain a view of the overall impact on consumption and the environment for the three irrigation methods, their ranking for a number of indicators have been summarized in Table 3. The results from this study show that the choice of irrigation method and pumping fuel source can greatly impact on resource consumption and environmental impact.

Table 3 shows that the $\mathrm{F}$ system operated by a diesel pump ranks lowest in terms of water use, water productivity, carbon emissions and change in depth to watertable. This system may be enhanced by improving flood irrigation layout to increase efficiency and converting to an electric pump using a "green power" source. This would have a number of effects, namely reducing the water applied, improving water productivity, reducing the change in water table depth and reducing emissions associated with pumping.

In this situation, the CP system ranks lowest in terms of energy productivity and net recharge. Improving yield and further improving the efficiency of the 
system may improve the ranking of this system against these indicators. The use of low pressure "bubbler" emitters in this case makes this CP system more energy efficient than CP systems which use high pressure sprays.

Table 3: $\quad$ Ranking of the three irrigation methods.

\begin{tabular}{lccc}
\hline & \multicolumn{3}{c}{ Irrigation method } \\
\hline Indicator & Flood & Centre Pivot & Sub-surface drip \\
Water use & 3 & 2 & 1 \\
Energy use & 1 & 2 & 3 \\
Water productivity & 3 & 2 & 1 \\
Energy productivity & 1 & 3 & 2 \\
Emissions & 3 & 1 & 2 \\
Water table change & 3 & 2 & 1 \\
Soil salinity change & 2 & 1 & 2 \\
\hline
\end{tabular}

The SSD system ranked worst in terms of energy use only. This could be improved by reducing the operating pressure of the system; however, this may result in compromising distribution uniformity if non-pressure-compensating drippers are installed in this system.

\section{Summary and conclusions}

The results of this study show that when an irrigated system is evaluated by more than just water consumption, its ranking among other methods can change. Given that current local and global concerns associated with agricultural production extend beyond just water consumption by a system, it has been demonstrated that by assessing systems against a range of indicators, a better understanding of the wide-spread consumptive and environmental impacts can be determined. In addition to this, areas for improvement can be identified and the impacts of these improvements across different categories explored. The decisions made at the paddock level can have wider implications on the environment. The appropriate selection of irrigation method and fuel source can lead to efficient and environmentally sound production systems at the local and regional levels.

\section{Acknowledgements}

The authors wish to acknowledge funding from Charles Sturt University and the Co-operative Research Centre for Irrigation Futures. On-farm data provided by Damian Smart is greatly appreciated. Help with determining appropriate parameters for SWAGMAN Farm by Tariq Rana is acknowledged.

\section{References}

[1] van der Werf, H.M.G., Tzilivakis, J.T., Lewis, K. \& Basset-Mens, C., Environmental impacts of farm scenarios according to five assessment methods. Agriculture, Ecosystems and Environment, 118, pp. 327-338, 2007. 
[2] Entry, J.A., Sojka, R.E. \& Shewmaker, G.E., Management of irrigated agriculture to increase organic carbon storage in soils. Soil Science Society of America Journal, 66 (6), pp. 1957-1964, 2002.

[3] Lal, R., Carbon emission from farm operations. Environment International, 30, pp. 981-990, 2004.

[4] Khan, S., Rana, T. \& Hanjra, M., A cross disciplinary framework for linking farms with regional groundwater and salinity management targets, Agricultural Water Management, 95, pp. 35-47, 2008a.

[5] Ozkan, B., Akcaoz, H., \& Fert, C., Energy input-output analysis in Turkish agriculture. Renewable Energy, 29, pp. 39-51, 2004.

[6] McInnes, K.L., Suppiah, R., Whetton, P.H., Hennessy, K.J. \& Jones, R.N. Climate Change in South Australia. Assessment of climate change, impacts and possible adaptation strategies relevant to South Australia, CSIRO Atmospheric Research: Victoria, 2003.

[7] Ozkan, B., Fert, C., Feyza Karadeniz, C., Energy and cost analysis for greenhouse and open-field grape production. Energy, 32, pp. 1500-1504, 2007.

[8] Hatirli, S., Ozkan, B., \& Fert, C., Energy inputs and crop yield relationship in greenhouse tomato production. Renewable Energy, 31, pp. 427-438, 2006.

[9] Mandal, K.G., Saha, K.P., Ghosh, P.K., Hati, K.M. \& Bandyopahyay, K.K., Bioenergy \& economic analysis of soybean-based crop production systems in Central India. Biomass \& Bioenergy, 23, pp. 337-345, 2002.

[10] FAO, The Energy and Agriculture Nexus, Food and Agricultural Organisation of the United Nations: Rome, Italy, 2000.

[11] Wells, C.M., Total Energy Indicators of Agricultural Sustainability: Dairy Farming Case Study FINAL REPORT, Report to MAF Policy, Dept. of Physics: University of Otago, 2001.

[12] Canakci, M., Topakci, M., Akinci, I., \& Ozmerzi, A., Energy use pattern of some field crops and vegetable production: Case study for Antalya region, Turkey. Energy Conversion and Management, 46(4), pp. 655-666, 2005.

[13] Barber, A., Seven Case Study Farms: Total Energy and Carbon Indicators for New Zealand Arable and Outdoor Vegetable Production, AgriLINK: New Zealand, 2004.

[14] Skewes, M., Treloar, N. \& Bailey, G., Irrigation Innovations in the South East of South Australia, Rural Solutions SA: Loxton, South Australia, No date.

[15] Jackson, T.M., Khan, S. \& Ahmad, A., Exploring energy productivity for a groundwater dependent irrigated farm using a system dynamics approach. In Oxley, L. and Kulasiri, D. (eds) MODSIM 2007 International Congress on Modelling and Simulation. Modelling and Simulation Society of Australia and New Zealand, pp. 156-162, 2007.

[16] Khan, S., O'Connel, N., Rana, T. \& Xevi, E., Hydrologic-Economic Model for Managing Irrigation Intensity in Irrigation Areas under Watertable and Soil Salinity Targets. Environmental Modeling and Assessment, 13 (1), pp. 115-120, 2008a. 